\title{
Effective management of severe radiation dermatitis after head and neck radiotherapy
}

\author{
Vijay Kumar, BSc, ${ }^{a}$ Ritesh Kumar, MD, ${ }^{b}$ Baby Rani Debnath, BSc, ${ }^{a}$ and \\ Suman Bhasker, $\mathrm{MD}^{\mathrm{b}}$ \\ Departments of ${ }^{a}$ Nursing and ${ }^{b}$ Radiotherapy, All India Institute of Medical Sciences, New Delhi, India
}

$\mathrm{H}$ ead and neck cancer is among the most prevalent cancers in developing countries. ${ }^{1}$ Most of the patients in developing countries present in locally advanced stages, and radical radiation therapy with concurrent chemotherapy is the standard treatment. ${ }^{1}$ Radiation therapy is associated with radiation dermatitis, which causes severe symptoms in the patient and can lead to disruption of treatment, diminished rates of disease control rates, and impaired patient quality of life. ${ }^{2}$ The management of advanced radiation dermatitis is difficult and can cause consequential late morbidity to patients. ${ }^{2}$ We report here the rare case of a patient with locally advanced tonsil carcinoma who developed grade 3 radiation dermatitis while receiving radical chemoradiation. The patient's radiation dermatitis was effectively managed with the use of a silver-containing antimicrobial dressing that yielded remarkable results, so the patient was able to resume and complete radiation therapy.

\section{Case presentation and summary}

A 48-year-old man was diagnosed with squamous cell carcinoma of the right tonsil, with bilateral neck nodes (Stage T4a N2c M0; The American Joint Committee on Cancer staging manual, 7th edition). In view of the locally advanced status of his disease, the patient was scheduled for radical radiation therapy at $70 \mathrm{~Gy}$ in 35 fractions over 7 weeks along. with weekly chemotherapy (cisplatin $40 \mathrm{mg} / \mathrm{m}^{2}$ ). During the course of radiation therapy, the patient was monitored twice a week, and symptomatic care was done for radiation-therapy-induced toxicities.

The patient presented with grade 3 radiation dermatitis after receiving $58 \mathrm{~Gy}$ in 29 fractions over 5 weeks (grade 0 , no change; grades 3 and 4, severe change). The radiation dermatitis involved the anterior and bilateral neck with moist desquamation of the skin (Figure 1). It was associated with severe pain, difficulty in swallowing, and oral mucositis. The patient was subsequently admitted to the hospital; radiation therapy was stopped, and treatment was initiated to ease the effects of the radiation dermatitis. Analgesics were administered for the pain, and adequate hydration and nutritional support was administered through a nasogastric tube. The patient's score on the Bates-Jensen Wound Assessment Tool (BWAT) for monitoring wound status was 44 , which falls in extreme severity status.

In view of the extreme severity status of the radiation dermatitis, after cleaning the wound with sterile water, we covered it with an antimicrobial dressing that contained silver salt (Mepilex AG; Mölnlycke Health Care, Norcross, GA). The dressing was changed regularly every 4 days. There was a gradual improvement in the radiation dermatitis (Figure 2 ). By day 10, the wound had healed significantly, and by day 16 , it was almost completely healed. The Bates-Jensen wound score and the pain score (visual analog scale) are shown in Table 1. Radiation therapy was withheld for 5 days and was resumed after the improvement of radiation dermatitis on day 5 (Figure 2), after which the patient completed his scheduled radiation therapy doses of $70 \mathrm{~Gy}$ in 35 fractions over 7 weeks with a gap of 5 days.

\section{Discussion}

Head and neck cancer is one of the most common cancers in developing countries. ${ }^{1}$ Most patients present with locally advanced disease, so chemoradiation is the standard treatment in these patents. Radiation therapy is associated with acute and chronic toxicities. The common radiation therapy toxicities are directed at skin and mucosa, which leads to radiation dermatitis and radiation mucositis, respectively. ${ }^{2}$ These toxicities are graded as per

Accepted for publication May 18, 2018. Correspondence: Ritesh Kumar, MD; riteshkr9@gmail.com. Disclosures: The authors report no disclosures or conflicts of interest. JCSO 2018;16(3):e156-e 158. Published online first, Month XX, 2018. (C)2018 Frontline Medical Communications. doi: https://doi.org/10.12788/jcso.0405 


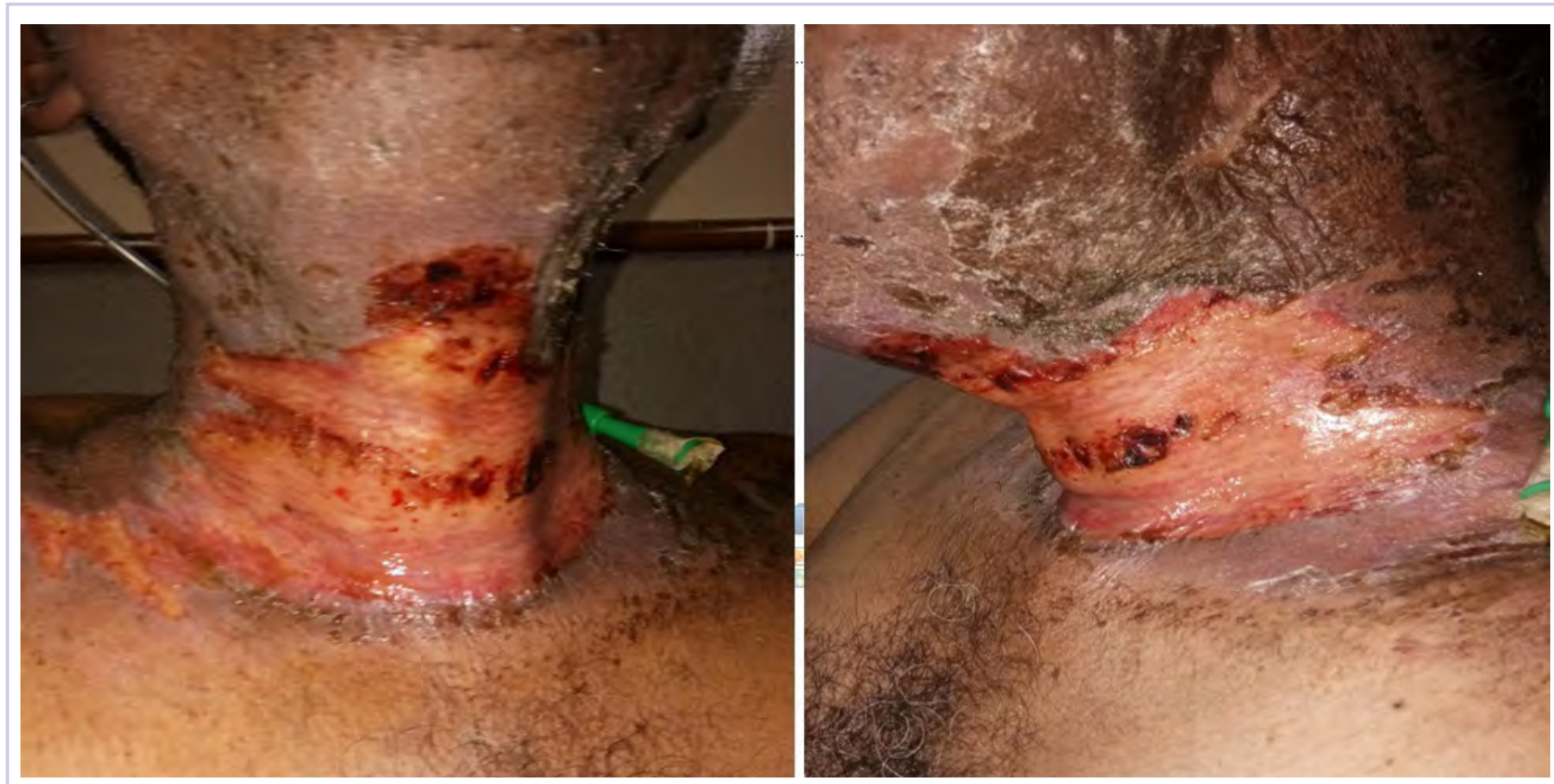

FIGURE 1 Acute grade 3 radiation dermatitis after 5 weeks of initiating radiation therapy.
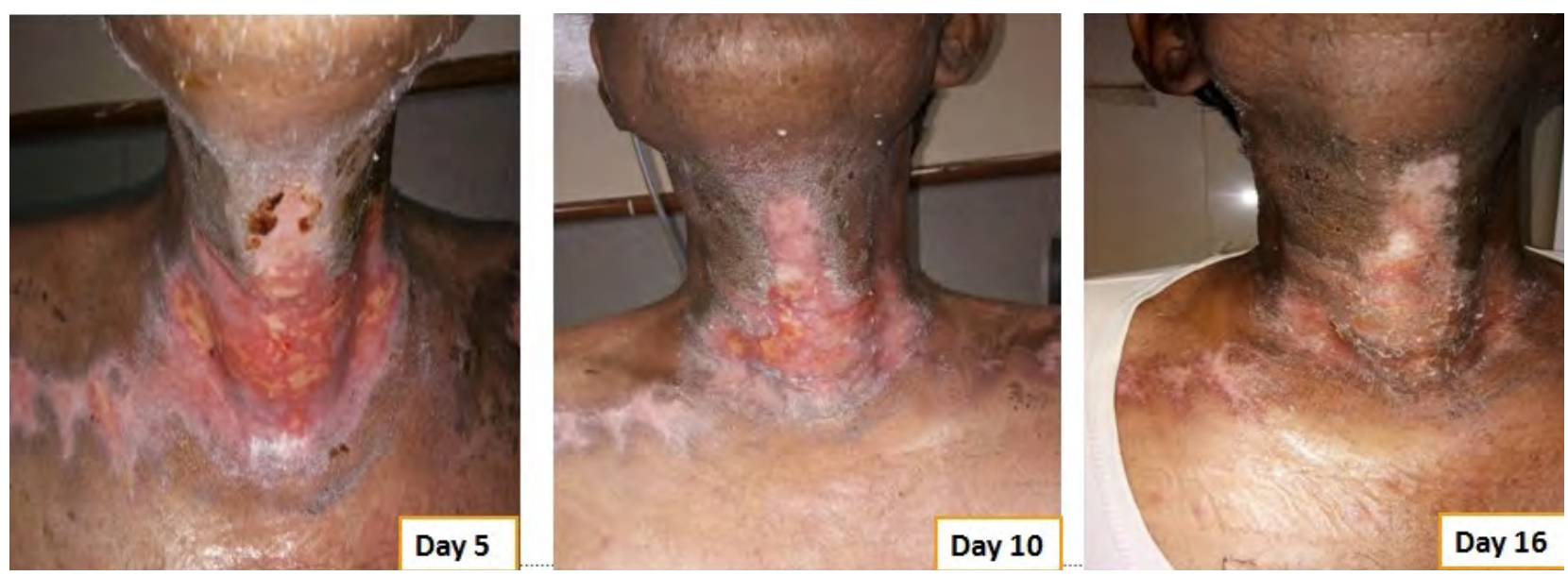

FIGURE 2 The healing phases of the radiation dermatitis at days 5, 10, and 16 .

the Radiation Therapy Oncology Group (RTOG) criteria (Table 2). ${ }^{3}$

Acute radiation dermatitis is radiation therapy dosedependent and manifests within a few days to weeks after starting external beam radiation therapy. Its presentation varies in severity and gradually manifests as erythema, dry or moist desquamation, and ulceration when severe. These can cause severe symptoms in the patient, leading to frequent breaks in treatment, decreased rates of disease control, and impaired patient quality of life. ${ }^{2}$ Apart from RTOG grading, radiation dermatitis can also be scored using the BWAT. This tool has been validated across many studies to score initial wound status and monitor the sub- sequent status numerically. ${ }^{4}$ The radiation dermatitis of the index case was scored and monitored with both RTOG and BWAT scores.

The management of advanced radiation dermatitis is difficult, and it causes consequential late morbidity in patients. A range of topical agents and dressings are used to treat radiation dermatitis, but there is minimal evidence to support their use. ${ }^{5}$ The Multinational Association for Supportive Care in Cancer treatment guidelines for prevention and treatment of radiation dermatitis have also concluded that there is a lack of sufficient evidence in the literature to support the superiority for any specific intervention. ${ }^{6}$ Management of radiation dermatitis varies 


\begin{tabular}{|lcc|}
\hline \multicolumn{2}{|c|}{ TABLE 1 Wound and pain scores, days 1 to 16} \\
Day & Wound score $^{\mathbf{a}}$ & Pain score $^{\mathbf{b}}$ \\
\hline 1 & 44 & 7 \\
\hline 5 & 29 & 5 \\
\hline 10 & 20 & 4 \\
16 & 13 & 3 \\
\hline
\end{tabular}

aBased on the Bates-Jensen Wound Assessment Tool (score range: 5-65, with 13 as wound regeneration and 60 as wound degeneration). ${ }^{\circ}$ Visual analog scale (score range: $0-10$, with 0 as no pain and 10 as worst pain).

TABLE 2 Radiation Therapy Oncology Group acute skin toxicity score

\begin{tabular}{ll} 
Score & \multicolumn{1}{c}{ Effects } \\
\hline 0 & No change over baseline \\
1 & $\begin{array}{l}\text { Follicular, faint or dull erythema/epilation/dry } \\
\text { desquamation/decreased sweating }\end{array}$ \\
2 & $\begin{array}{l}\text { Tender or bright erythema, patchy moist des- } \\
\text { quamation/moderate edema }\end{array}$ \\
3 & $\begin{array}{l}\text { Confluent, moist desquamation other than skin } \\
\text { folds, pitting edema }\end{array}$ \\
4 & Ulceration, hemorrhage, necrosis
\end{tabular}

among practitioners because of the inconclusive evidence for available treatment options.

The use of silver-based antimicrobial dressings has been reported in the literature in the prevention and treatment of radiation dermatitis, but with mixed results. ${ }^{7}$ Such dressings absorb exudate, maintain a moist environment that promotes wound healing, fight infection, and minimize the risk for maceration, according to the product informa-

\section{References}

1. Simard EP,Torre LA, Jemal A. International trends in head and neck cancer incidence rates: differences by country, sex and anatomic site. Oral Oncol. 2014;50(5):387-403.

2. Hymes SR, Strom EA, Fife C. Radiation dermatitis: clinical presentation, pathophysiology, and treatment 2006. J Am Acad Dermatol. 2006;54(1):28-46.

3. Cox JD, Stetz J, Pajak TF. Toxicity criteria of the Radiation Therapy Oncology Group (RTOG) and the European Organization for Research and Treatment of Cancer (EORTC). Int J Radiat Oncol Biol Phys. 1995;31(5):1341-1346.

4. Harris C, Bates-Jensen B, Parslow N, Raizman R, Singh M, Ketchen R. Bates-Jensen wound assessment tool: pictorial guide validation project. J Wound Ostomy Continence Nurs. 2010;37(3):253-259.

5. Lucey P, Zouzias C, Franco L, Chennupati SK, Kalnicki S, McLellan BN. Practice patterns for the prophylaxis and treatment of acute radiation dermatitis in the United States. Support Care Cancer. 2017;25(9):2857-2862.

6. Wong RK, Bensadoun RJ, Boers-Doets CB, et al. Clinical prac- tion sheet. ${ }^{8}$ Clinical study findings have shown silver to be effective in fighting many different types of pathogens, including Methicillin-resistant Staphylococcus aureus and other drug-resistant bacteria.

Aquino-Parsons and colleagues studied 196 patients with breast cancer who were undergoing whole-breast radiation therapy. ${ }^{9}$ They showed that there was no benefit of silver-containing foam dressings for the prevention of acute grade 3 radiation dermatitis compared with patients who received standard skin care (with moisturizing cream, topical steroids, saline compress, and silver sulfadiazine cream). However, the incidence of itching in the last week of radiation and 1 week after treatment completion was lower among the patients who used the dressings.

Diggelmann and colleagues studied 24 patients with breast cancer who were undergoing radiation therapy. ${ }^{10}$ Each of the erythematous areas $(n=34)$ was randomly divided into 2 groups; 1 group was treated with Mepilex Lite dressing and the other with standard aqueous cream. There was a significant reduction in the severity of acute radiation dermatitis in the areas on which Mepilex Lite dressings were used compared with the areas on which standard aqueous cream was used.

The patient in the present case had severe grade 3 acute radiation dermatitis with a BWAT score indicative of extreme severity. After cleaning the wound with sterile water, instead of using the standard aqueous cream on the wounds, we used Mepilex AG, an antimicrobial dressing that contains silver salt. The results were remarkable (Figure 2 and Table 2). The patient was able to restart radiation therapy, and he completed his scheduled doses.

This case highlights the effectiveness of a silver-based antimicrobial dressing in the management of advanced and severe radiation dermatitis. Further large and randomized studies are needed to test the routine use of the dressing in the management of radiation dermatitis. tice guidelines for the prevention and treatment of acute and late radiation reactions from the MASCC Skin Toxicity Study Group. Support Care Cancer. 2013;21(10):2933-2948.

7. Vavassis P, Gelinas M, Chabot Tr J, Nguyen-Tân PF. Phase 2 study of silver leaf dressing for treatment of radiation-induced dermatitis in patients receiving radiotherapy to the head and neck. J Otolaryngology Head Neck Surg. 2008;37(1):124-129.

8. Mepilex Ag product information. Mölnlycke Health Care website. http://www.molnlycke.us/advanced-wound-care-products/antimicrobial-products/mepilex-ag/\#confirm. Accessed May 3, 2018.

9. Aquino-Parsons C, Lomas S, Smith K, et al. Phase III study of silver leaf nylon dressing vs standard care for reduction of inframammary moist desquamation in patients undergoing adjuvant whole breast radiation therapy. J Med Imaging Radiat Sci. 2010;41(4):215-221.

10. Diggelmann KV, Zytkovicz AE, Tuaine JM, Bennett NC, Kelly LE, Herst PM. Mepilex Lite dressings for the management of radiationinduced erythema: a systematic inpatient controlled clinical trial. Br J Radiol. 2010;83(995):971-978. 